\title{
Reflexões sobre educação, alteridade e violência a partir da concepção de constituição subjetiva em Levinas
}

\author{
Reflections about education, alteration and violence from the \\ conception of subjective constitution in Levinas
}

\section{Reflexiones sobre educación, alteridad y violencia desde la concepción de constitución subjetiva en Levinas}

\author{
Uanderlei Carbonara' \\ Universidade de Caxias do Sul, Professor no Programa de Pós-graduação em Educação
}

Resumo: Neste artigo se propõe explorar a concepção levinasiana de constituição da subjetividade na perspectiva de um pensamento contemporâneo em superação às filosofias da consciência da modernidade. Nesse percurso de exploração da subjetividade constituinte, ganha especial atenção o tema da sensibilidade, ao qual Emmanuel Levinas associa o despertar ético da humanidade. Ao longo do texto especula-se uma possível explicação descritiva para a manifestação da violência nas primeiras manifestações da formação do Eu, ainda anterior à sua plena constituição subjetiva. $\bigcirc$ argumento para tal é de que o Eu que se ocupa do mundo como posse e satisfação não está ainda em condições de perceber a presença de Outrem como alteridade, mas toma-o como ameaça à sua manutenção no mundo. Para derivar uma reflexão educacional sobre alteridade e violência analisa-se, em especial, o potencial do conceito levinasiano de sensibilidade, associado às concepções de acolhimento e Rosto.

Palavras-chave: Constituição da subjetividade. Emmanuel Levinas. Educação. Alteridade. Violência.

Abstract: The article proposes to explore the Levinasian conception about the constitution of the subjectivity in the perspective of a contemporary thought in overcoming to the philosophies of the consciousness of the modernity. In this course of exploration of the constituent subjectivity special attention is paid to

Doutor em Educação pela Pontifícia Universidade Católica do Rio Grande do Sul; Mestre em Filosofia pela Pontifícia Universidade Católica do Rio Grande do Sul. 
the theme of sensitivity, to which Emmanuel Levinas associates to the ethical awakening of humanity. Throughout the text it is speculated a possible descriptive explanation for the manifestation of violence in the first manifestations of the formation of the Self, still previous to its full subjective constitution. The argument for this is that the self that deals with the world as possession and satisfaction is not yet in a position to perceive the presence of the Other as alterity, but takes it as a threat to its maintenance in the world. In order to derive an educational reflection on alterity and violence, it is analyzed in particular, the potential of the Levinasian concept of sensitivity, associated to the reception and Face conceptions.

Keywords: Constitution of subjectivity. Emmanuel Levinas. Education. Alterity. Violence.

Resumen: Elartículo propone explorar la concepción levinasiana de constitución de la subjetividad en la perspectiva de un pensamiento contemporâneo que supere las filosofías de la conciencia de la modernidade. En esa trayectoria de explotación de la subjetividad constituyente gana especial atención el tema de la sensibilidad, al que Emmanuel Levinas asocia el despertar ético de la humanidad. En el transcurso del texto se especula una posible explicación descriptiva para la manifestación de la violencia en las primeras manifestaciones de la formación del Yo, como manifestación aún anterior a su plena constitución subjetiva. El argumento para ello es que el Yo que se ocupa del mundo como posesión y satisfacción no está todavía en condiciones de percibir la presencia de Outrem como alteridad, sino que lo toma como amenaza a su mantenimiento en el mundo. A fin de desplegar una reflexión educativa sobre alteridad y violencia se analiza, en especial, el potencial del concepto levinasiano de sensibilidad, asociado a las concepciones de acogida y Rostro. A fin de desplegar una reflexión educativa sobre alteridad y violencia se analiza, en especial, el potencial del concepto levinasiano de sensibilidad, asociado a las concepciones de acogida y Rostro.

Palabras clave: constitución de la subjetividade. Emmanuel Levinas. Educación. Alteridad. Violencia. 


\section{INTRODUÇÃO}

Osforço em compreender as expressões de violência e, desse modo, encontrar meios de evitá-las tem sido empreendido com afinco em diversos setores da sociedade, inclusive com intensa participação dos meios acadêmicos. Se, por um lado, há resultados sociais bastante expressivos na prevenção à violência em segmentos específicos, por outro lado percebe-se que a violência recria seus meios de expressão continuamente e mostra-se como presença ininterrupta na história da humanidade. Ao nosso tempo já nos parece claro que não está em questão mais abordar o tema da violência como externo à sociedade que atenta aos seus processos civilizatórios. Nossos esforços serão mais profícuos se nos concentrarmos em pensar a violência como uma das expressões históricas das sociedades e, desse modo, como constituinte de muitos dos nossos modos de relação. Isso não significa uma resignação à violência, mas possibilita uma mudança de perspectiva: não mais buscar algum tipo de solução ou cura a um mal que nos vem de fora para nos afetarnos em nossa interioridade, mas buscar no interior dos ideais civilizatórios a gênese dessas expressões contrárias à própria civilidade almejada. Tal esforço pode ser empreendido em diferentes matrizes de estudo: éticas, políticas, epistemológicas, históricas, sociológicas, antropológicas, psicológicas e linguísticas. Desse amplo conjunto de possibilidades, no artigo que ora se apresenta propõe-se um recorte muito específico: investigar possíveis relações entre violência e educação a partir de uma reflexão ética orientada pela ideia de alteridade. Trata-se de um estudo sobre a gênese do humano, e, nessa abordagem, busca-se evidenciar a violência a partir de tal constituição. Não se trata de um estudo que se proponha a gerar teorias sobre ações de combate à violência, mas situa-se num momento anterior: compreender a constituição humana em nós e a possível presença da violência de algum modo expressa no contexto dessa gênese.

A abordagem em questão toma uma perspectiva filosófica particular. As considerações que se seguirão sobre violência e educação estarão orientadas a partir do pensamento de Emmanuel Levinas, filósofo lituano-francês que publicou suas principais obras ao longo da segunda metade do século XX. 
Especialmente com Levinas pretende-se traçar um percurso pela constituição da subjetividade e dessa argumentação derivar algumas pistas de reflexão sobre a gênese da violência. No adiantar da exposição desenvolvem-se alguns argumentos, ainda inspirados em Levinas, mas já para além das abordagens específicas do autor, sobre possíveis compreensões dos processos formativos e a distinção de quais ações educativas podem ser mais propícias ao encontro humano e, portanto, menos propícias à perpetuação da violência. Como já foi preliminarmente anunciado, o intuito aqui não é propor ações de prevenção ou combate à violência, mas buscar, numa orientação fenomenológico-descritiva, esclarecimentos sobre sua gênese em nossa condição humana. $\bigcirc$ mais próximo a que aqui se poderá chegar a qualquer teoria da ação está naquilo que a autocompreensão humana nos possibilita ao discernimento sobre nosso agir diante do outro.

\section{CONSIDERAÇÕES PRELIMINARES SOBRE A UIOLÊNCIA}

De pronto cabe já explicitar sobre quais das manifestações da violência este artigo toma como orientação temática. Das manifestações as quais chamamos de violência nos interessa pensar a negação do outro como outro. Nesse sentido, a violência é uma reificação: o outro é reduzido a algo inorgânico e desprovido de consciência. Ou seja, a uma coisa da qual posso dispor. Cabe também explicitar que não se está aqui pensando a violência como decorrência de plena consciência daquele que a pratica. Pois nem sempre aquele que realiza a ação violenta compreende o alcance do seu agir. Isso porque o outro não é uma obviedade. Dar-se conta da presença do outro como inteiramente outro só será possível num sujeito maduramente constituído.

Tomemos como exemplo o mito hebraico dos irmãos Caim e Abel, narrado no primeiro livro da Bíblia ( $G$ n 4, 1-16). Os dois irmãos querem agradar a Deus com suas oferendas: frutos da terra e sacrifício de animais. Quando Caim percebe que os animais sacrificados por Abel agradaram mais a Deus do que os frutos da terra que ele ofertara, sente-se tomado de irritação 
e mata o irmão mais novo. Aqui nos interessa em especial o diálogo que se trava a seguir entre Deus e Caim. Quando Caim é interpelado por Deus com a pergunta: "Onde está teu irmão Abel?", ele responde: "Não sei. Acaso sou guarda do meu irmão?". Verdadeiramente Caim não se sente responsável pela vida de seu irmão. $\bigcirc$ ato violento do assassinato, nesse caso, é acima de tudo um ato de afirmação de si. Caim ainda não é capaz de reconhecer Abel como um outro, mas apenas como um obstáculo que se coloca frente aos seus objetivos. Portanto, na base do mito hebraico sobre o primeiro assassinato está a reificação que demonstra a incapacidade de se perceber o outro como outro. Possivelmente esse mito ainda tem muito a nos dizer nos dias atuais: uma parcela importante da violência praticada nas relações sociais ancorase numa perspectiva reificante em relação às vítimas. Não perceber o outro na ação, mas dominar ou eliminar um objeto qualquer, é o que justifica essa manifestação de violência.

A violência, em muitas das suas demonstrações, volta-se a alguém a quem não se percebe o rosto, a alguém a quem não importa qual seja o seu dizer. Nessa dimensão a violência age, não sobre um outro, mas sobre algo, sobre o que possa ser objetivado e objetificado e, portanto, dominado ou eliminado. É nesse contexto de percepção sobre a violência como negação do outro como outro que se propõe uma tarefa investigativa que congrega dois momentos: primeiro abordar alguns pontos do pensamento ético-filosófico da obra de Emmanuel Levinas; e num segundo momento conjecturar sobre uma possível compreensão da relação entre educação e violência a partir do conceito de alteridade.

\section{DA SENSIBILIDADE À ALTERIDADE}

Emmanuel Levinas destacou-se intelectualmente pelo modo como elaborou a ideia de alteridade. Comumente referido como filósofo da ética da alteridade, Levinas é, antes disso, um filósofo da subjetividade. Isso porque seu percurso fenomenológico faz uma descrição da constituição da subjetividade 
de modo distinto ao que fora concebido pelas filosofias da consciência, e acentua a intersubjetividade como condição para que o Eu assim se reconheça. Eu afirmado desde si, em Descartes; como autônomo, em Kant; ou numa dialética de reconhecimento com o Tu, em Hegel; é sempre resultado último da consciência. Diferentemente da modernidade, o pensamento contemporâneo encontra elementos em Nietzsche, Heidegger, Freud e no segundo Wittgenstein que, de modos distintos, propõe a superação da filosofia da consciência e do sujeito moderno. Vattimo (2007), por exemplo, interpreta o anúncio nietzschiano acerca da morte de Deus como anúncio da morte do sujeito e pontua com Heidegger a necessidade de uma saída da metafísica humanista. Honneth (2009), por sua vez, credita à psicanálise e ao giro linguístico a derrocada de qualquer vestígio do sujeito moderno sustentado na consciência. Diante dessa ruptura em relação à subjetividade, Levinas afasta-se das filosofias da consciência, mas também não se associa aos movimentos contemporâneos que decretam a morte do sujeito.

A alternativa levinasiana de superação do sujeito centrado na consciência passa pela afirmação de uma subjetividade justificada na intersubjetividade. $\bigcirc$ que ganhará o nome de Ética da Alteridade é uma perspectiva filosófica que admite a primazia do Outro sobre o Mesmo e da Responsabilidade (dimensão intersubjetiva) sobre a Liberdade (dimensão subjetiva). Ainda assim, cabe lembrar que Levinas não propõe qualquer teoria da ação, mas orienta sua produção intelectual ao exercício fenomenológico de descrição do humano. Sua teoria ética, portanto, não visa direcionar o agir segundo este ou aquele critério, mas descrever o que em nós nos constitui humanos.

Em especial aqui se dará ênfase à concepção levinasiana sobre a gênese ética do humano como acolhimento ao Rosto e daí para a compreensão da alteridade. É nesse aspecto da obra do autor que se quer concentrar as reflexões sobre violência e paz. Caim, o personagem mítico que assassina o irmão, age com violência porque ainda lhe falta a ética. Ou ainda: porque ainda lhe falta constituir-se humano. Toma importância a concepção de que a Ética inaugura em nós a humanidade. $\bigcirc$ Eu não se funda em um só tempo num ato criador de si. Mas a constituição subjetiva desenvolve-se até um despertar ético. 
Vejamos, num percurso breve, como Levinas descreve a constituição subjetiva. Diferentemente das filosofias da consciência que vinculam a gênese da subjetividade a um exercício racional (subjetividade fundada na consciência), Levinas parte de uma ideia de encarnação (subjetividade concebida a partir da sensibilidade). $O$ sujeito é corpo, sua carne e seu sangue põem em curso sua constituição subjetiva. Portanto, suas relações com o mundo - como a fome, a sede, a dor e o prazer - estão no começo da formação do Eu. Levinas afirma, em Totalidade e Infinito, que o homem se sacia de comida e bebida, toma posse das coisas do mundo, estabelece sua morada e faz-se feliz. A essa experiência eminentemente corpórea, Levinas chama-a gozo (juissance) e ao gozo da vida vincula a independência do Eu à continuidade de uma condição cósmica. Por isso, afirma o autor que a "subjetividade tem sua origem na independência e na soberania do gozo." (LEVINAS, 2008, p. 117). Ao gozo Levinas vincula a ideia da vida feliz. Essa vida feliz, no entanto, ainda não tem dimensão ética, pois até então o Eu se limita a resistir à dominação e assimilação do mundo. Levinas refere-se a esse momento como egoísmo. Não um egoísmo moral, mas uma solidão de quem depende de si mesmo para afirmar o seu Eu. Toda a existência ainda é "uma existência para si [...] como é para si 'barriga vazia não tem ouvidos', capaz de matar por um bocado de pão" e, nesse sentido, "o gozo é uma retirada para dentro de si, uma involução." (LEVINAS, 2008, p. 122123). Nesse ponto do desenvolvimento subjetivo o Outro ainda não é percebido como tal. Mas, ao contrário, toda a estranheza soa como algum tipo de ameaça. A violência, portanto, é uma possibilidade de resistência do homem que se vê necessitando afirmar sua posse do mundo. Aqui está em questão não uma ideia de violência como deliberação consciente, mas como expressão do Mesmo que se afirma em sua independência e por isso resiste a tudo quanto lhe possa parecer como oposição ao seu Eu.

Enfatize-se uma vez mais que não há ainda conteúdo moral nesse egoísmo original. Mas também ainda não há humanidade e, portanto, ainda não há ética. Mas é dessa vida feliz como gozo do mundo que afeta a pele, que poderá ter origem a sensibilidade. Sensibilidade aqui pensada como sensualidade que nasce na pele que é tocada, das coisas do mundo que são possuídas como satisfação do corpo. Escreve Levinas: "A sensibilidade 
que descrevemos a partir do gozo do elemento não pertence à ordem do pensamento, mas àquela do sentimento, isto é, da afetividade que dá calafrios ao egoísmo do eu." E, logo a seguir, completa acentuando o caráter sensual: "Não se conhece, mas vivem-se as qualidades sensíveis: o verde das folhas, a vermelhidão de um pôr-do-sol." (LEVINAS, 2008, p. 119). Observe-se que tudo isso ainda é anterior à consciência e, portanto, não há intencionalidade. Em lugar de qualquer intencionalidade essa sensibilidade guarda uma dimensão de passividade de quem é afetado pelo mundo e em que se desperta o desejo.

Cabe acentuar que está sendo apresentada uma ideia de subjetividade que se origina no prazer de gozar a vida. E cabe também lembrar que todo o prazer é finito. E porque finda o prazer sentido é que se deseja gozá-lo novamente. Assim acontece com a fome - gozo na satisfação da necessidade - que, quando saciada, renascerá como desejo de nova satisfação em voltar a saciar-se. E também assim como a carícia sobre a pele não faz desaparecer o desejo, mas incita a desejar nova carícia. É, pois, a finitude do gozo que torna premente perpetuá-lo como duração. A relação com o mundo, então, é temporal e guarda na finitude do prazer um sentido de existir.

Em Levinas a vida feliz guarda em si uma condição paradoxal em relação à constituição da subjetividade: se, no egoísmo da saciedade com a posse das coisas há espaço para a violência como modo de resistir ao mundo e às estranhezas (como a atitude de Caim), é preciso também considerar que será essa vida feliz que abrirá a possibilidade do nascimento de uma tal sensibilidade que permitirá ao Outro agora se mostrar em sua alteridade. Observe-se que resistência e sensibilidade estão na gênese da subjetividade levinasiana: a primeira como manutenção do eu em si, a segunda como possibilidade de abertura à exterioridade. A sensibilidade está para além da resistência, mas só se afirma porque há resistência. $\bigcirc$ que se poderá chamar de subjetividade ética e acolhimento a outrem, em Levinas, só é possível num Eu seguro de si. E a sensibilidade atua nessa passagem do Eu centrado em si para a já referida abertura à exterioridade. Segundo Levinas, da sensibilidade brota um desejo para além da saciedade, um desejo pelo que não se pode possuir e, por isso, movimento de abertura à estranheza. E é nessa dimensão 
que a ética e a humanidade terão vez. Na constituição subjetiva a sensibilidade possibilita a humanidade do homem e, por conseguinte, a ética.

A sensibilidade cria algo como uma fenda na estrutura original do Eu. Se o primeiro movimento de constituição do Eu era resistência e satisfação, pela sensibilidade abre-se outra possibilidade: um desejo - sem pretensão de saciedade - pelo mistério de quem é estranho. Agora o Outro já não é mais uma ameaça à manutenção do Eu, mas é uma possibilidade de existência para fora do Eu. O que a sensibilidade permite perceber é que o Outro não pode ser englobado como posse, tal como as coisas do mundo. Enquanto as coisas do mundo são tomadas para si, o Outro permanece inapreensível e, portanto, alteridade. Trata-se de um outro Eu que não está aí para mim e do qual não posso dispor. E, diferentemente das coisas do mundo, que podem ser objetificadas, o Outro se mostra sempre numa áurea de mistério. Não se pode saber do Outro senão aquilo que ele se dá a conhecer. Aqui Levinas lança mão da categoria do Rosto (Visage): pelo Rosto o Outro manifestase. Dar-se conta de um Outro que se dá a conhecer é diferente do que a intencionalidade com que se apreende qualquer objeto. A relação com o Rosto que se mostra só pode alcançar algum êxito como passividade e nunca como intencionalidade.

A ética nasce - e aqui a humanidade funda-se - como passividade possibilitada pela sensibilidade em que o Eu se coloca frente ao Outro como abertura à sua manifestação. Segundo Levinas (2008, p. 178), a "epifania do rosto é ética." É importante salientar que no exercício fenomenológico de descrição da humanidade, o autor vincula a plena constituição subjetiva - que se realiza como acolhimento a outrem que se mostra - à responsabilidade ética. E nesse contexto argumentativo já não mais haverá lugar para a violência. Diante do Outro, que se mostra como mistério, o Eu reconhece-se refém. E essa dimensão acentua-se sobretudo quando o Outro se expressa em sua fragilidade. Frente ao faminto que me apela por alimento, a sensibilidade me coloca diante de duas possibilidades: ou alimentá-lo ou abandonar a humanidade. Perante a fragilidade do Rosto que apela não há outra resposta humana senão a responsabilidade. 
Enfim, no percurso fenomenológico levinasiano demonstra-se que a construção da subjetividade alcança seu momento mais elevado na abertura à intersubjetividade a partir da qual o Mesmo se reconhece inteiramente refém de outrem. E isso nos permite dizer que somos humanos porque nos constituímos eticamente. Daí a ideia de que a ética funda em nós a nossa humanidade. Disso também decorre que, enquanto não nos reconhecermos imersos nessa responsabilidade ética por outrem, ainda não há humanidade plena em nós.

\section{ENTRE A ÉTICA E A PERSISTÊNCIA DA UIOLÊNCIA}

Observe-se que há um risco em se afirmar que a violência está na esteira de uma incompletude na constituição subjetiva do eu como humano. Uma leitura mais aligeirada do tema poderia sugerir algum tipo de casta inferior ou outra hierarquização nas relações interpessoais. Faz-se importante salientar que dessa descrição do humano não se poderá derivar qualquer tipo de estratificação moral a partir da qual as pessoas possam ser classificas como sendo de nível ético mais ou menos satisfatório. $\bigcirc$ percurso descritivo que Levinas assume em relação à subjetividade, em que há um momento em que o sujeito não se percebe ainda humano, de modo algum poderá servir para que se afirme algum tipo de deficiência existencial ou distúrbio crônico de personalidade. Não está em questão diagnosticar a eticidade alheia ou avaliar quaisquer graus de moralidade. Em questão está um processo humano de constituição do Eu que ainda está aberto ao desenvolvimento. E isso nos conduz a um aspecto do pensamento levinasiano ao qual aqui receberá forte conotação pedagógica: o que importa é o acolhimento que se possa oferecer a outrem, aquém de qualquer julgamento. Mas também não poderíamos nos alienar sob o pretexto de um discurso filosófico sobre a ética que origina a humanidade e, sob a égide do acolhimento, desconsiderarmos o fenômeno da violência social em suas manifestações persistentes em muitas formas de relações humanas. 
Como Levinas ocupa-se em fazer uma fenomenologia do humano, e não uma fenomenologia da violência, não encontramos em seus textos um percurso que explicite como e porque a violência ocorre e persiste em muitas relações humanas. ${ }^{2}$ Também não é o propósito deste artigo fazer tal percurso descritivo. Mas parece ser pertinente ressaltar que a nossa condição humana, em sua fragilidade, está sempre sob a ameaça da violência. Não sem razão, Levinas recorrentemente lança mão do mandamento hebraico "Não matarás!" (ou ainda: "Não cometerás assassinato!") como um apelo necessário de ser feito em favor da vida. Em Levinas, o "Não matarás!" encarna-se como apelo que se manifesta num rosto frágil. É o faminto que apela pelo alimento para não morrer de sua falta, a criança que apela por cuidados para poder viver, o ancião que apela para não ser esquecido em sua velhice. A leitura levinasiana sobre o mandamento bíblico remete a uma responsabilidade incondicional para com a vida de outrem.

Como em Levinas não está proposta uma teoria da ação, então não caberia aqui querer derivar preceitos ou recomendações que evitassem a violência. Mas se considerarmos a descrição da constituição humana, então será possível que esse desenvolvimento até a ética nos oriente por um percurso reflexivo distinto daquele da persistência da violência. E a ideia de sensibilidade, como é pensada em Levinas, terá algo muito importante para nos dizer. Ou seja: partindo-se da descrição do autor sobre a constituição subjetiva e sabendo-se que os processos educativos têm grande potencial de participação no desenvolvimento humano de cada sujeito, então aventa-se que concepções educativas que deem especial atenção à sensibilidade e à promoção de experiências de acolhimento terão maior potencial de contribuir para que se reduza a persistência de manifestações de violência nas relações humanas.

\footnotetext{
2 A título de esclarecimento: ainda que tenha sido afirmado que Levinas não faça uma fenomenologia da violência, é bem verdade que um olhar ao conjunto da obra do autor permite que a análise da violência avance também por sua crítica à ontologia, à totalidade e à ideia de sistema. Em sua crítica à ontologia, Levinas chegará a referir o mal como excesso de Ser. Tal investigação permitiria ainda explorar outros aspectos no debate entre ética e violência, para além do que está sendo aqui abordado. Porém, por uma opção de delimitação de abordagem, aqui a argumentação ficará restrita à constituição da subjetividade, com ênfase à sensibilidade. Os possíveis pontos aqui indicados merecem um outro estudo que amplie o presente artigo.
} 


\section{EDUCAÇÃO E ALTERIDADE}

$\bigcirc$ percurso argumentativo apresentado até aqui evidenciou que, em Levinas, a sensibilidade cumpre papel decisivo em nossa constituição subjetiva. A partir dessas considerações podemos nos perguntar: qual é a importância da sensibilidade no processo de formação humana? Ora, se concordarmos com o autor acerca da relação entre sensibilidade e constituição subjetiva, então caberá pensarmos nas distintas e variadas ações educativas que realizamos e avaliar qual é relevância dada à sensibilidade nesse processo. E, ainda, se pensarmos nas ações educativas especificamente nos ambientes escolares, então nesses espaços igualmente valerá a relevância que atribuirmos à sensibilidade. Sem querer aqui estender por demais o que, por si só, já seria tema de um outro estudo mais amplo, propõe-se pensar, a partir de Levinas, numa perspectiva formativa que ultrapasse experiências escolares restritas a etapas de instrução para o conhecimento e alcance um sentido mais amplo de formação humana que contemple a sensibilidade como aspecto central. Na base disso está uma educação que abandona quaisquer perspectivas de controle e se reconhece temporal e finita, incapaz de garantir ideais formativos. A partir desse ponto poder-se-á vislumbrar uma educação aberta a possibilidades plurais.

Assim como não há garantias em relação ao comprometimento ético que se possa esperar de um sujeito, também não haverá em relação aos fins que a educação poderá promover. Mas somente a abertura a possibilidades plurais decorrentes de experiências formativas é que guardará, dentre essas possibilidades, o despertar ético para a alteridade. Isso porque uma experiência escolar que se apresente com pretensões de controle de seus resultados é, em si mesma, já uma ação violenta que nega a alteridade. A sensibilidade, nesse sentido, está no nascimento do sujeito ético, do sujeito capaz de acolher o estranho em sua alteridade e responder responsavelmente ao apelo do seu rosto. E à educação cabe pensar-se a partir da imprevisibilidade da sensibilidade em que se origina a ética. Trata-se, portanto, de educação sem telos, sem ideais e sem qualquer pretensão de controle sobre o processo formativo de quem é 
educado. Importa, nesse sentido, muito mais o acolhimento que a educação possa promover do que o legado que pretenda deixar ao educando.

Proponho que pensemos, inclusive, numa prática escolar bastante consolidada em muitas de nossas instituições de ensino, inclusive universitárias. É bastante comum entrarmos em salas de aula e encontrarmos classes e cadeiras organizadas em fileiras voltadas ao espaço reservado ao professor. Pensemos essa sala de aula repleta de estudantes. $\bigcirc$ que o estudante sentado ao fundo da sala terá à sua frente? Provavelmente um professor voltado com o rosto para ele e muitos colegas dos quais saberá relatar a silhueta de seus cabelos e costas, mas não os seus rostos. Ressalte-se, é claro, que não importa tanto acentuar uma prática escolar isoladamente. Mas não é difícil perceber que esse formato mais habitual de distribuição dos estudantes em salas de aula parte de um pressuposto de que o outro importa pouco. Ou, ao menos, não parece haver preocupação em promover o encontro com o olhar do outro. Não será exagero afirmar que, ainda que atenuemos responsabilidades individualizadas devido ao caráter consuetudinário de tal organização escolar, essa é uma prática escolar de incitação à indiferença e permissividade de violência. Também não é o caso de se afirmar que a mudança na distribuição do mobiliário numa sala de aula por si só vá evitar a recorrência social da violência, mas é importante considerar que o encontro com o rosto do outro é uma das mais óbvias experiências autenticamente formativas. Por isso não há como justificar ética ou pedagogicamente que o espaço destinado à educação e à formação possa ser concebido à revelia da promoção do encontro de olhares. Para além de particularidades contextuais, importa argumentar em favor da ideia de que está intrínseco à ideia de formação a relação com o outro. Portanto, a ação educativa não será suficientemente exitosa se descuidar-se da promoção do encontro humano entre seus partícipes. Por isso é que se afirma que, ao negligenciar as condições mais favoráveis ao encontro humano, em vez de estimular o acolhimento, abre-se precedente para legitimar a indiferença diante do outro. E a indiferença ao outro - no percurso argumentativo que aqui vem sendo apresentado - é o que permite o sujeito a agir com violência. 
Ainda mais grave do que as fileiras de classes em salas de aula são as práticas pedagógicas, tanto na educação básica quanto na superior, que visam formar crianças e jovens para a inovação e o empreendedorismo. Sob a empolgação do efêmero de um discurso por demais refém de seu tempo, pessoas são constrangidas aos valores mercadológicos da competitividade e da individualidade financeira. Esses valores tendem por reforçar um tipo de iniciativa individual na qual o outro não é propriamente outro, mas apenas um meio para um fim. Nesse caso será prudente admitir que já há antecedentes do mesmo tipo nos ambientes escolares em algumas práticas recorrentes de competições esportivas e, sobretudo, em ranqueamentos sobre o desempenho dos estudantes em relação aos conteúdos apreendidos e às habilidades comprovadas em exames. Situações como essas pouco favorecem um processo autenticamente formativo e, ao contrário disso, estimulam a negação do rosto do outro. Portanto, esse conjunto de práticas diretamente pedagógicas que assumem a competitividade como pressuposto de suas ações educativas acaba muito mais promovendo a indiferença e a violência do que possibilidades de encontro humano eticamente justificável. Nesse ponto cabe ressaltar que é preciso ter atenção às sutilezas de como discursos eufóricos de modernização na educação introduzem conceitos e práticas oriundos de segmentos sociais já adaptados a operar com a exclusão como dispositivo para alcançar seus êxitos. Ainda que haja significativa condescendência social para uma competitividade em que o êxito de um sustenta-se sobre o fracasso ou a derrota de outro, não será difícil perceber que está aí suposta uma tolerância à indiferença. E estender essa condescendência a ações pedagógicas embasadas na competitividade - o que, por vezes, chega até a empolgar pais e professores - implica negligenciar uma perspectiva formativa de acolhimento humano.

Ora, se com Levinas temos elementos para pensar uma constituição subjetiva em que o despertar ético é antecedido por um sujeito que ainda não é capaz de reconhecer a alteridade para, então, posteriormente, incitado pela sensibilidade, acolher o Outro que se mostra, parece plausível que daí se possa derivar algum indicativo sobre o papel da educação. Embora Levinas não associe a sua descrição da subjetividade a processos de desenvolvimento humano (e há um cuidado do autor em não operar com objetivações do humano), não será 
de todo incorreto derivar possíveis relações entre algumas características das etapas de desenvolvimento infantil e juvenil e o possível despertar ético. Nessa tímida relação, sem qualquer pretensão de objetivar a formação, cabe indicar a quem se proponha às tarefas educativas que as atenções estejam sempre voltadas à promoção de condições do encontro entre rostos. Isso porque será mais plausível que modos de organização curricular e didático que privilegiem o encontro humano tragam alguma possibilidade de contribuição à formação ética, do que outros modos de organização que privilegiem o isolamento entre os sujeitos. Ou seja, numa derivação do pensamento levinasiano, uma autêntica formação será aquela que favorecer o despertar ético. Isso, é claro, sem qualquer pretensão redentora da educação, pois o despertar ético não é algo que possa de algum modo ser garantido por quem educa, mas é possibilidade de acontecimento singular em cada sujeito.

Em questão está que a saída de modelo educacional fundado na subjetividade imanente e um ingresso na perspectiva orientada pela sensibilidade e pelo acolhimento à alteridade incluem o abandono de um projeto civilizatório idealizado para abrir espaço a relações menos determinadas e mais abertas ao inusitado de cada encontro humano. E se os muitos ideais formativos determinados pelas melhores intencionalidades civilizatórias viram-se frustrados pela perpetuação de uma violência que acaba por se manifestar de dentro de suas próprias estruturas, é de bom tom agora tomar em consideração uma outra perspectiva formativa aberta à pluralidade desde a sensibilidade.

\section{CONSIDERAÇÕES SOBRE EDUCAÇÃO, ALTERIDADE E PAZ}

Retomemos o relato hebraico sobre o assassinato cometido por Caim. $\mathrm{Na}$ narrativa, antes da consumação do assassinato, Deus repreende Caim por estar aborrecido e não levantar a cabeça. ${ }^{3}$ Temos, portanto, um Caim

\footnotetext{
3 Gn 4, 6. Em diferentes traduções desse versículo bíblico também encontramos outras expressões que se complementam na expressão de sentido: Caim é admoestado por estar com seu rosto ou
} 
ensimesmado que toma o mundo como um "para si". E é com essa reclusão sobre si mesmo que Caim convidará o irmão a ir aos campos, onde Abel será morto. $\bigcirc$ relato mítico permite interpretá-lo como narrativa de um fratricídio em que o assassino não permitiu a seu irmão manifestar-se em seu rosto. A violência caímica é anterior à constituição de uma subjetividade ética, pois o personagem se relaciona com o mundo apenas como possibilidade de satisfação, sem ainda adentrar o mundo da sensibilidade: ele quer ser feliz, satisfazendo-se no mundo, indiferente a quem quer que seja. Abel, portanto, não é Outro que se possa mostrar, mas ameaça às satisfações do irmão. Abel é apenas um concorrente que compete com Caim pelas atenções divinas. Tratase de um fratricídio sem encontro, sem acolhimento, sem humanidade. Ao que parece, pelo relato, ambos os irmãos andavam muito ocupados em agradar a Deus e importava menos o encontro de um com o outro. E o diálogo entre Deus e Caim revela a ausência da ética: "Onde está teu irmão Abel?"; ao que se ouve a resposta: "Não sei. Acaso sou guarda do meu irmão?". Sobre esse ponto escreve Levinas (1997, p. 151-152): "A resposta de Caim é sincera. Em sua resposta só falta a ética; nela só há ontologia: eu sou eu e ele é ele." Ante a humanidade de Abel, Caim está indiferente. E é isso que aqui está sendo abordado como uma manifestação da violência anterior à ética.

Dentre as possíveis aprendizagens que podemos elaborar a partir desse relato mítico, há uma delas a que não poderíamos nos descuidar: é mais formativo que nos ocupemos com o rosto de quem nos é próximo, em lugar de nos ocuparmos em agradar com oferendas qualquer de nossas divindades às custas da invisibilidade compulsória do outro. As práticas pedagógicas que foram anteriormente comentadas talvez poderiam ser, em parte, comparadas à condição dos irmãos do mito hebraico. Por estarem por demais ocupados em apresentar oferendas às suas divindades, muitas crianças e jovens não chegam a perceber a possibilidade de um encontro humano original com o outro que lhe é próximo. E mais preocupante ainda é perceber que algumas instituições educacionais e as práticas de alguns educadores estão muito mais a serviço de demandas financistas e mercadológicas do que

semblante abatido, e também por estar com o rosto transtornado. Em comum às traduções consultadas está a indicação de um Caim ensimesmado. 
voltados à promoção de uma formação que favoreça o encontro humano. Não raras vezes estudantes são estimulados a se ensimesmarem em razão da competitividade que está intrínseca a alguns processos educativos. Até mesmo alguns projetos organizados em equipes favorecem mais a que se tomem os supostos parceiros como meios para alcançar interesses, do que efetivamente promovam acolhimento ao diferente. É preocupante ver crianças e jovens, em espaços e atividades educativos, buscando como parceiros de equipes aqueles que são mais úteis às vitórias competitivas e desprezando pessoas de menor utilidade aos fins buscados. Com certeza, se de fato queremos que os processos formativos contribuam mais para a promoção da ética do que para a perpetuação da violência, então algumas coisas precisarão ser seriamente revisadas nos modos de proceder em educação. É bem verdade que não é possível apontar qualquer solução segura e eficiente para que se contenha a violência persistente nas relações sociais. E pretendê-lo como resultado de metas e objetivos seria já uma violência, pois seria preciso adequar as diferenças a algum padrão de igualdade idealizada.

Mas, de modo mais específico, se nos ocuparmos em refletir sobre possíveis contribuições da educação para uma convivência mais pacífica, então poderíamos recorrer à sensibilidade levinasiana e pensarmos o quanto à educação cabe permitir que o autêntico encontro humano aconteça. E aqui parece já ser coerente afirmar que se espera de um espaço destinado a promover a formação humana que o encontro com o rosto do outro seja mais valorizado do que a resolução individual de um teorema ou qualquer outra expressão de devoção a um saber ou a uma autoridade constituída.

\section{REFERÊNCIAS}

HONNETH, A. Crítica del agravio moral: Patologías de la sociedad contemporánea. Tradução Peter Storandt Diller. Buenos Aires: Fondo de Cultura Económica, Universidad Autónoma Metropolitana, 2009.

LEVINAS, E. Entre nós: ensaios sobre a alteridade. Tradução Pergentino S. Pivatto. Petrópolis: Vozes, 1997.

LEVINAS, E. Totalité et infini. Essai sur l'exteriorité. Paris: Kluwer Academic, 2008. 
VATTIMO, G. O fim da modernidade: niilismo e hermenêutica na cultura pós-moderna. 2. ed. Tradução Eduardo Brandão. São Paulo: Martins Fontes, 2007.

Recebido em: 26 de outubro de 2017 Aceito em: 03 de abril de 2018

Endereço para correspondência: Francisco Getúlio Vargas, 1130, Petrópolis, 95070-560, Caxias do Sul, Rio Grande de Sul, Brasil, caixa-postal 1352; vanderlei.carbonara@ucs.br 